\title{
Differences in Distress, Emotion Regulation, and Quality of Life Among Asian and White Breast Cancer Patients
}

\author{
T.Torres ${ }^{1}$, K. C. Vaca ${ }^{4}$, E. Hofmeister ${ }^{1}$, H. Shen ${ }^{1}$, \\ D. W. Blayney ${ }^{2}$, S. Kesler ${ }^{3}$, O. Palesh ${ }^{1}$
}

1. Stanford University, Psychiatry and Behavioral Sciences, Stanford, CA, USA

2. Stanford University, Medicine Oncology, Stanford, CA, USA

3. University of Texas at Austin, Cancer Neuroscience Lab, Austin, TX, USA

4. PGSP-Stanford Psy.D. Consortium, Palo Alto University, Palo Alto, CA, USA

\section{BACKGROUND}

The breast cancer

experience has

detrimental and long-term

effects on quality of life.

Specifically, Asian/Asian American breast cancer survivors report lower quality of life (QOL) when compared with White survivors (Le et al., 2017; Qian et al., 2017).

Asian/Asian American survivors also report more depressive symptoms and poorer emotion regulation (Ashing-Giwa et al., 2011; Marroquin et al., 2016 ).

However, most of these outcomes have been solely studied during survivorship.

Little is known about whether these disparities begin during treatment.

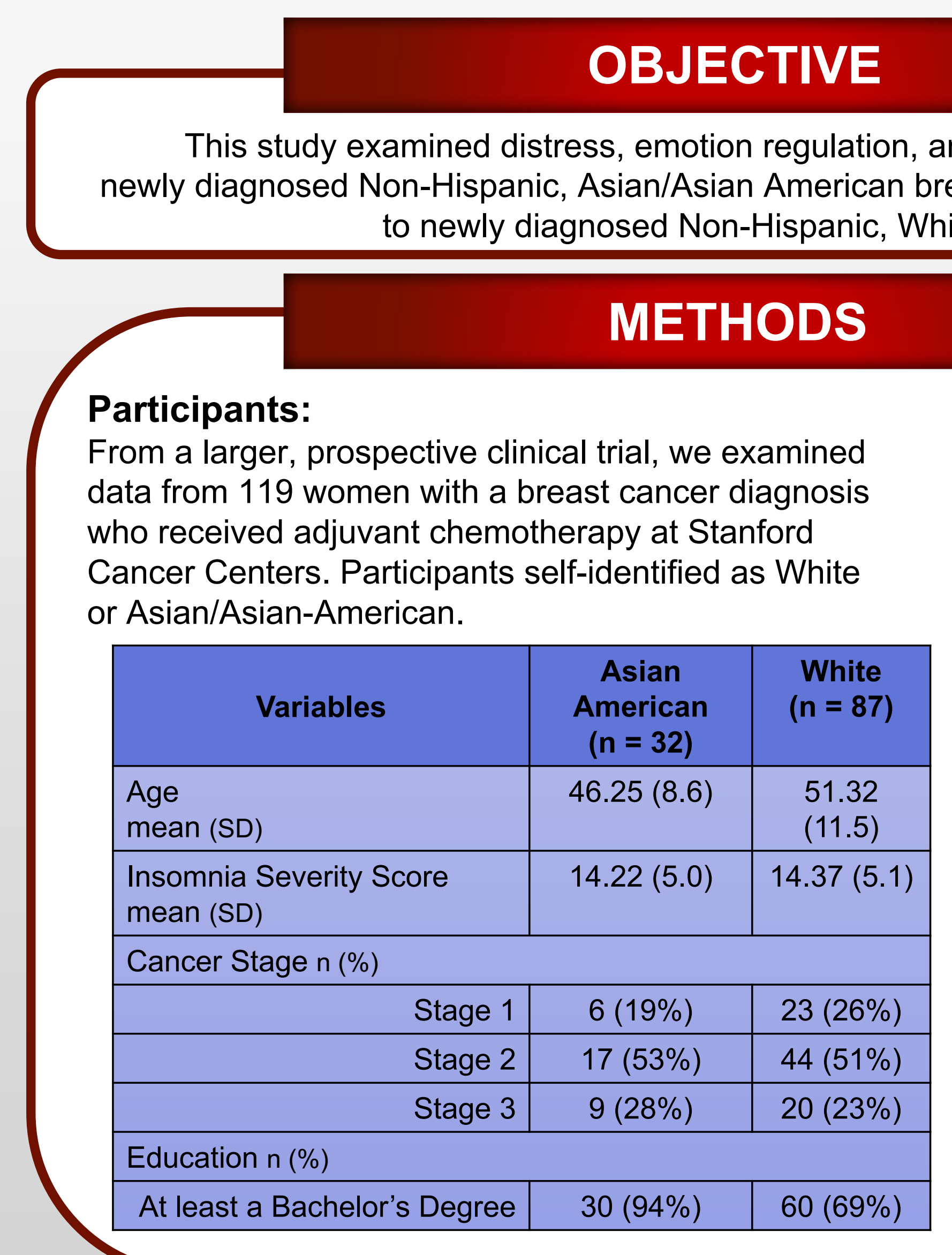

\section{OBJECTIVE}

This study examined distress, emotion regulation, and quality of life (QOL) in to newly diagnosed Non-Hispanic, White patients.

\section{METHODS}

\section{Participants:}

From a larger, prospective clinical trial, we examined data from 119 women with a breast cancer diagnosis who received adjuvant chemotherapy at Stanford Cancer Centers. Participants self-identified as White .

\begin{tabular}{|c|c|c|}
\hline Variables & $\begin{array}{c}\text { Asian } \\
\text { American } \\
(n=32)\end{array}$ & $\begin{array}{l}\text { White } \\
(n=87)\end{array}$ \\
\hline $\begin{array}{l}\text { Age } \\
\text { mean (SD) }\end{array}$ & $46.25(8.6)$ & $\begin{array}{l}51.32 \\
(11.5)\end{array}$ \\
\hline $\begin{array}{l}\text { Insomnia Severity Score } \\
\text { mean (SD) }\end{array}$ & $14.22(5.0)$ & $14.37(5.1)$ \\
\hline \multicolumn{3}{|l|}{ Cancer Stage n (\%) } \\
\hline Stage 1 & $6(19 \%)$ & $23(26 \%)$ \\
\hline Stage 2 & $17(53 \%)$ & $44(51 \%)$ \\
\hline Stage 3 & $9(28 \%)$ & $20(23 \%)$ \\
\hline \multicolumn{3}{|l|}{ Education $\mathrm{n}(\%)$} \\
\hline At least a Bachelor's Degree & $30(94 \%)$ & $60(69 \%)$ \\
\hline
\end{tabular}

\section{Measures:}

Participants reported on levels of distress, emotion regulation, and cancerrelated quality of life.

\section{CAD:}

a 50 -item self-report questionnaire measuring depression/anxiety symptomatology.

\section{DERS:}

a self-report measure assessing levels of difficulties with regulating emotions.

\section{EORTC QLQ-C30:}

a self-report designed to assess the quality of life of cancer patients.

\section{RESULTS}

- Among all patients, significant correlations were found between more distress symptoms, greater difficulties in emotional regulation, and lower QOL.

- Moreover, Asian/Asian American patients experienced higher distress ( $g=$ $.440, p=.035)$, more difficulties in regulating their emotions $(g=.627, p=$ $.003)$, and lower overall QOL ( $g=.517, p=.014)$ compared to White patients.

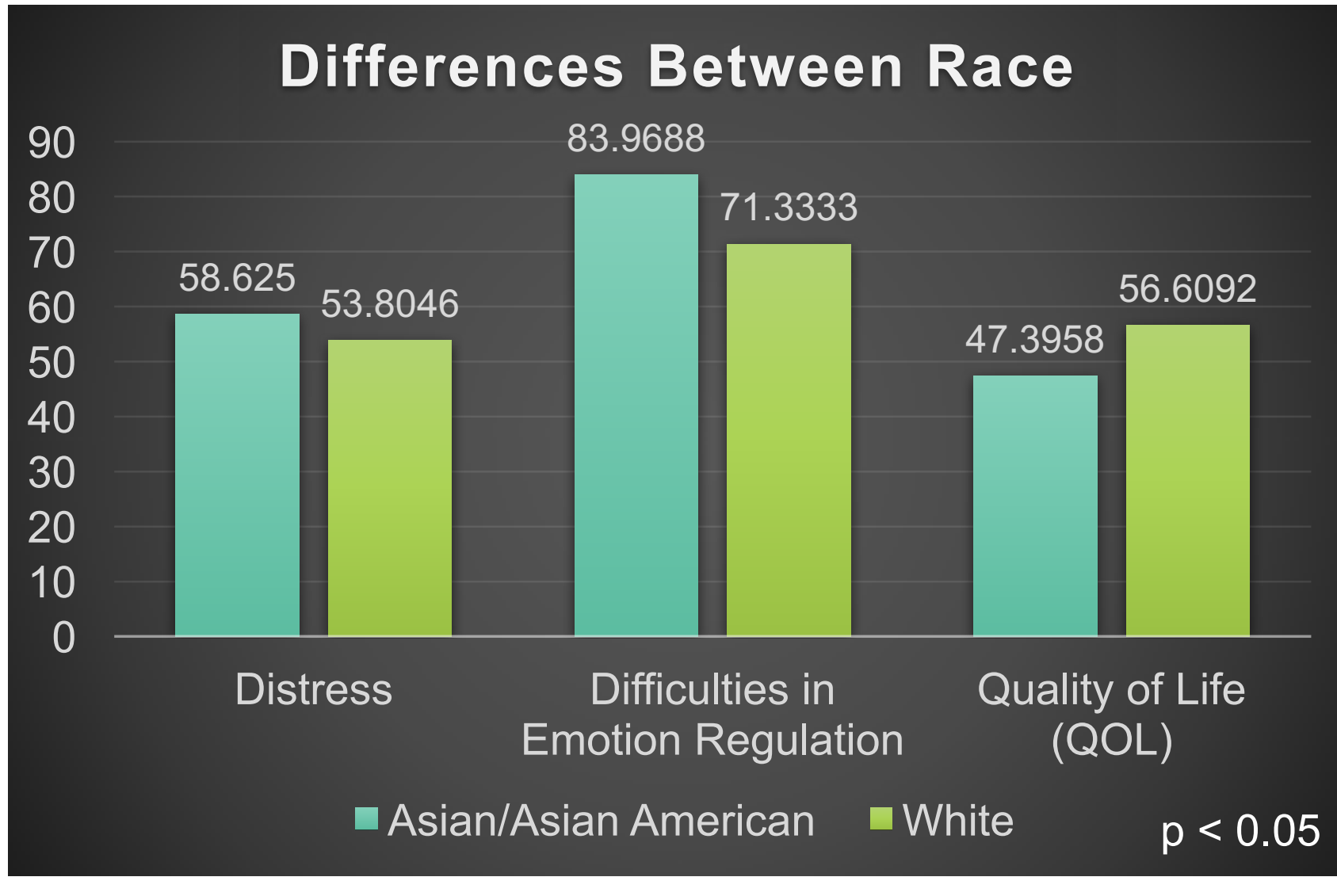

\section{.}

regulation, elevated distress symptoms, and poor QOL do occur during chemotherapy, and are more pronounced in Asian/Asian American breast cancer patients compared to White patients.

- These findings suggest that Asian/Asian Americans fare worse, even before survivorship.

- Future studies should examine the factors contributing to these disparities and ways to better support Asian/Asian American breast cancer patients and survivors. 